\title{
Leadership and branding in business schools: a Bourdieusian analysis
}

Rajani Naidoo ${ }^{\mathrm{a}}$, Jonathan Gosling ${ }^{\mathrm{b}}$, Richard Bolden ${ }^{\mathrm{c}}$, Anne O’Brien ${ }^{\mathrm{b}}$ and Beverley Hawkins ${ }^{\mathrm{b}}$

${ }^{a}$ School of Management, University of Bath, UK

${ }^{b}$ Centre for Leadership Studies, University of Exeter Business School, UK

${ }^{c}$ Department of Organisation Studies, University of West of England, UK

Corresponding author: Rajani Naidoo <edsrn@management.bath.ac.uk>

Accepted for publication in Higher Education Research and Development, 33(1), 126-138, Spring 2014.

\section{Acknowledgements}

We would like to thank Mats Alvesson, Michael Beverland, Janet Borgerson, Jonathan Schroeder and Scott Taylor for their contribution to the research and theory from which this paper was developed. We are also grateful to Bruce Macfarlane and the three anonymous reviewers for their constructive feedback on the first draft of this paper. 


\title{
Leadership and branding in business schools: a Bourdieusian analysis
}

\author{
This paper explores the growth of corporate branding in higher education and its use by \\ academic and professional managers as a mechanism for not only enhancing institutional \\ reputation but also for facilitating internal culture change. It uses Bourdieu's framework of field, \\ capital and habitus to analyse case studies of branding in two English business schools from the \\ perspectives of academics, management and professional staff and students. The findings reveal \\ a number of tensions and inconsistencies between the experiences of these groups that highlight \\ the contested nature of branding in this sector. In an era of rankings, metrics and student fees, it \\ is suggested that branding has become an important means through which HE leaders and \\ managers (re)negotiate the perceived value of different forms of capital and their relative \\ positions within the field. Whilst branding operates at a largely ideological level it has a \\ material effect on the allocation of power and resources within institutions. This is an important \\ development in a sector that has typically privileged scientific capital, and contributes towards \\ an understanding of the ways in which leadership is 'distributed' within universities.
}

Keywords: leadership, branding, identity, habitus, field, capital, Bourdieu

\section{Introduction}

The past decade has seen a veritable explosion of interest in brand reputation within UK higher education (HE). In this paper we suggest that, as institutions compete for finite resources on a global scale, branding has become adopted by institutional leaders not only as a means for marketing their products and services to potential 'customers' (Hemsley-Brown \& Oplatka, 2006) but also as a mechanism for facilitating organisational change. Whilst strategic positioning within the HE landscape has always been a key concern for universities what is new, we argue, is the manner in which the diffuse concept of 'reputation' has been overtaken by a more concrete conceptualisation of 'brand' and the extent to which a range of institutional actors (both existing and new) have become actively engaged in the construction, 
communication and (attempted) control of their organisation's 'brand image'. The following quote from the Times Higher Education magazine captures the essence of branding in HE:

\footnotetext{
Institutions know that, in a sense, the degrees they confer are worth only as much as their brand. In nations where tuition fees are established, students "buy" a brand that will appeal to the right businesses when it is time to find a job; their choice of university will become part of their own "brand identity". To attract the right calibre of academics, a university relies on its brand. And when those same academics submit a proposal for research funding or a paper to a leading journal, the brand of their institution may play a role in how their research is judged. The university's brand becomes part of their own brand as an academic. (Morgan, 2011)
}

In this paper we use Pierre Bourdieu's $(1977,1986)$ conceptual framework of field, capital and habitus to illustrate how the use of branding as a leadership and managerial device for leveraging institutional change in universities is associated with shifting power dynamics and a renewed struggle around the valorisation and devalorisation of particular forms of capital. From a Bourdieusian perspective, HE reform and the construction of quasi-markets has eroded traditional mechanisms for governing universities and transformed them into organisational actors responsible for the strategic management of reputation. This has in turn led to the perception of the brand as a strategic asset capable of distilling and projecting core organisational attributes and values. Within this context, university leaders and managers have become brand agents - responsible for maintaining, developing and, where necessary, changing perceptions of brand image by key stakeholders. In particular, in an ideological context where universities have been positioned by some as irrelevant ivory towers held in stasis by producer monopoly, it has been argued that opening up the sector to market forces and implementing managerial mechanisms from the corporate world will enhance HE functioning (Deem \& Brehony, 2005; Naidoo, Shankar \& Veer, 2011). In this sense branding can be positioned as a strategy that reflects a modern and forward-looking management and 
leadership approach. However, as research on academic leadership has shown (see Lumby, 2012 for a review) the expectations and aspirations of staff, students, and others, differ in significant ways - especially with regards to the importance attributed to different forms of capital and their subsequent impact on identity and performance.

Whilst, as an activity, branding is becoming increasingly prevalent within universities (Jevons, 2006; Temple, 2006) research into the links between branding and leadership is still under-developed. As Hemsley-Brown \& Goonawardana (2007) suggest, empirical investigations are rare and in general focus on how brand attributes influence student choice of university. With the exception of Waeraas \& Solbakk (2009) and Forbes (2012) there is little research on internal branding and even less on how various stakeholder groups interact in relation to branding work. Our study contributes to this literature through an exploration of how branding practices, imported from the business sector, are recontextualised within HE and the implications for academics, managers, professional staff and students.

To make this point we draw on empirical evidence from two English business schools. We use these as examples to illustrate how, in each case, (re)branding was employed by the dean and his/her team as part of an intentional strategy to both raise the external profile of the school and to facilitate a change in organisational culture. We also consider the response of staff and students to these initiatives. Such analysis is relevant to the theme of this special issue on 'leading the academy' by shedding light on how branding shapes conceptions of academic work and influences power relations. Through an emphasis on identity, values and purpose, branding has the potential to influence at an ideological level (something often associated with 'leadership') rather than through the more mechanistic route of workload allocation models and performance management systems (practices more likely to be characterised as 'management'). This is an interesting and important development that 
contributes to an understanding of the ways in which leadership is 'distributed' within HE and the ability or inability of various actors to exert agency (Gosling, Bolden \& Petrov, 2009; Lumby, 2013).

\section{Method}

This article draws on data collected at two research-intensive English business schools as part of a larger study on leadership and branding in HE. Given the diversity of the sector we do not suggest that these cases are 'representative' but they are interesting illustratively for a number of reasons.

Whilst similar in size, age, location, disciplinary mix and reputation these schools differed in terms of their approach towards leadership and management - with School A being rather more 'collegial' and School B more 'managerialist'. There were also close similarities in terms of the history of branding - with both showing little explicit attempt at branding prior to the appointment of a new dean. We chose to focus on business schools because of their tendency to be at the forefront of branding and marketing activity in HE and on researchintensive universities due to the greater likelihood of tensions arising between research and teaching that would make the articulation of a single identity more challenging. In both institutions data was collected between 2009-2010 - a period of intense refocusing on markets in English universities in the run up to the 2012 increase in the fee cap for undergraduate students.

In each case a variety of sources were used, as indicated in Table 1. Interviews lasted on average 45 minutes, with questions covering a range of themes including: perceptions of the brand; tensions and contradictions in the brand; emotional and cognitive responses to the brand; personal and professional practices related to branding work; perceived links between the brand and school/institutional strategy; and the impact of branding on academic work. 
Despite the common themes, there was some flexibility in how interviews were conducted in order to allow adaptation to the respondent and probing on key issues. Informed consent was secured from all research participants although names of individuals and institutions have been anonymised in this article.

\begin{tabular}{|c|c|c|}
\hline Data source & School A & School B \\
\hline $\begin{array}{l}\text { Institutional } \\
\text { documentation }\end{array}$ & $\begin{array}{l}\text { Brand identity and style guide; } \\
\text { school website; brochures... }\end{array}$ & $\begin{array}{l}\text { Business school strategy; branding } \\
\text { review; website; prospectuses }\end{array}$ \\
\hline $\begin{array}{l}\text { Academic } \\
\text { faculty }\end{array}$ & Interviews with dean... & $\begin{array}{l}\text { Recorded interviews with dean and } \\
\text { a senior lecturer; informal } \\
\text { discussion with approximately } 10 \\
\text { other academics in a variety of roles }\end{array}$ \\
\hline $\begin{array}{l}\text { Professional } \\
\text { staff }\end{array}$ & Interviews with... & $\begin{array}{l}\text { Recorded interviews with marketing } \\
\text { manager and two professional } \\
\text { support staff; informal discussion } \\
\text { with approximately five other } \\
\text { professional service staff }\end{array}$ \\
\hline Students & $\mathrm{xxx}$ & $\begin{array}{l}\text { Written assignments from } \\
\text { approximately } 50 \text { second year } \\
\text { undergraduate students; written } \\
\text { comments from } 51 \text { postgraduate }\end{array}$ \\
\hline
\end{tabular}




\begin{tabular}{|l|l|l|}
\hline & $\begin{array}{l}\text { students on the school brand; } \\
\text { recorded interviews with two } \\
\text { doctoral students }\end{array}$ \\
\hline
\end{tabular}

Table 1: Data sources

Data analysis was conducted through an open-ended process of thematic coding and crossreferencing across different sources. In particular, two key aspects of the branding process were identified: developing and articulating the brand, and interpreting the brand. The first of these gives a broadly historical account of the branding process, whilst the second offers the potential to compare and contrast the perspectives of different stakeholders.

In the discussion section we use a Bourdieusian framework to interpret the cases due to its potential to help make sense of complicated, contextualised branding practices.

According to Bourdieu, social formations are structured around a complex ensemble of social fields in which various forms of power circulate (Bourdieu, 1977). In Bourdieu's research the field of university education is conceptualized as one with a high degree of autonomy in that it generates its own values and behavioural imperatives that are relatively independent from forces emerging from the economic and political fields. It is a field structured in hierarchy in the sense that agents and institutions occupy dominant and subordinate positions. These positions depend on the amount of specific resources (which Bourdieu terms 'capital') that are possessed (Bourdieu, 1986). Bourdieu distinguishes between two forms of capital: 'academic capital', which is linked to power over the instruments of reproduction of the university body, and 'scientific capital', which is linked to research and intellectual renown (Bourdieu, 1988). Bourdieu develops an understanding of the operation of practices occurring in HE by the use of the concept of 'strategy', which is understood as a specific orientation of practice. Strategy is dependent on 'habitus', which as a result of socialization engenders in 
individuals a 'disposition' below the level of consciousness to act or think in certain ways; and on the network of objective relations between positions that agents or institutions occupy in the field (Bourdieu, 1996).

Deploying Bourdieu's framework, each school is conceptualised as a field within which individuals and groups are located hierarchically according to the amount and types of capital they possess. Scientific capital (held by research active scholars) has historically bestowed greater power in the field of HE. However in recent years the increased significance of market forces and managerial practices has enhanced the position of other forms of capital including economic capital and the academic capital possessed by those in managerial positions (Naidoo, 2003). The field of HE, therefore, is neither static nor the product of consensus but one of permanent conflict in which agents and organisations individually or collectively implement strategies in order to improve or defend their positions in relation to other occupants. The construction, responses and practices related to branding thus function within each of our case study schools as a locus of contestation; at the heart of which is the struggle to determine the legitimate types of capital that bestows institutional power in the institutional field of business schools and individual power in the organisational context of the case study organisations.

\section{Findings}

In the following sub-sections we outline the processes through which the brand has been developed and articulated, and interpreted in each business school. For confidentiality, the accounts have been collated and pseudonyms allocated.

\section{a) Developing and articulating the brand}


A number of similarities can be traced between the processes by which 'branding' became an explicit and significant part of the business schools' approach to articulating and legitimising their position both within the university and the wider field of HE. For both schools (re)branding efforts were championed by newly appointed deans who regarded this as a mechanism through which to implement a revised strategy, as illustrated in the following quote from one of the deans.

\footnotetext{
I think the first thing we did was almost internally in the university... I was the first person to lead the business school because it hadn't been there before and I had to do a lot of branding initiatives shall we say, like... with the university centre and that was what we did in the [strategic review]... to say right, the business school is this, this is where it sits, who are its competitors, and so on. So the first thing was to establish it within the parent institution, which was key.
}

As indicated above, in each case the brand development process was associated with a repositioning of the school in relation to the university. Whilst both regarded their university membership as a key part of their strategic advantage, they also sought a high degree of autonomy in how they presented themselves.

Both deans regarded rankings on university league tables and school accreditations (such as the EQUIS award from the European Foundation for Management Development (EFMD) and the Association to Advance Collegiate Schools of Business' (AACSB) school accreditation) as key indicators of their schools' status and strategic priorities when it came to brand reputation.

\footnotetext{
[When I arrived we had no accreditation] in a way it's a catch-up... but the school should have had that three or four years ago, not so much AACSB but certainly EQUIS, but it didn't ... I think the key elements I would like to convey are quality and that comes from being in a quality university.
}

In order to facilitate this strategic repositioning both business schools endeavoured to convey a shift to a more professional approach in how they engaged with students and partners. 
Branding efforts were supported through the recruitment of corporate relations directors (or equivalent) and accompanied by the appointment of external experts to develop the 'brand image'. In School A, for example, a consultancy company was employed to work with professional administrators to develop a Brand Identity and Style Guide that prescribed the key messages and values that should be conveyed and the 'tone of voice' to be used in all communications. It also specified the logo design and application for all stationery and developed a PowerPoint template for presentations. Colour palettes were assigned for promotional material relating to particular academic programmes.

Associations and partnerships with other business schools were another important part of the (re)branding process in terms of the kinds of organisations with which they collaborated. In both cases, the business schools sought to position themselves as members of an elite group involved in world-class teaching and research, a point conveyed in the following quote from the quality and accreditation officer at School B.

'Our partnerships now are only with people who are EQUIS accredited so we're branding by association in effect.'

Physical manifestations of the brand were also evident at each school - in the school buildings, documentation and websites. At School A wall plaques, photographs and audiovisual displays highlighted key corporate partners and profiles of individual students. At School B similar features were evident, as well as an extensive building and renovation project upgrading the appearance and quality of teaching, research and social spaces.

Analysis of websites, promotional materials, brochures and interviews with academic and professional managers revealed key intended features of the brand. What was striking at both schools was that branding work took a range of forms from explicit marketing and promotion to reputation building and knowledge exchange. 
To further to signal membership of an elite group, and differentiation from the nonelite sector, both schools went to great lengths to stress their academic profile, status and character. The dean's message on the School A website, for example, referred to 'research intensivity', 'innovation', 'knowledge creation', 'scholarship' and 'excellence'. In much of the general written material, research excellence appeared to form a fulcrum around which other features of the branding message were located. Furthermore, research was linked to real world application and synergies between research and teaching identified as enhancing the relevance and the quality of teaching. At School B, personal sound-bites were collected from all academic staff for the website on issues including 'how do you make a difference to researchers/students/the wider business world?'

Both schools also sought to convey their international profile by highlighting the diversity of faculty and students, international partnerships and arrangements for overseas student placements and exchanges. In each school student profiles were in evidence around the building, with statements of how their studies have enhanced their career prospects. Similarly, both schools emphasised their friendliness, support and the accessibility of academic staff, as well as the attractive environment in which they were situated.

\section{b) Interpreting the brand}

The section above focused on how and why branding activities were developed and the messages they sought to convey about the school to external audiences. An important insight from this study, though, was that in both cases branding was also being used as a vehicle for internal culture change. The focus in this section is on how branding was received internally. We explore how staff and students perceived brand messages and values and how interpretations varied according to their roles and identities. 
A degree of scepticism was evident in the responses of academic staff in both institutions. They expressed difficulty in distinguishing 'branding' from 'image', 'vision' and 'reputation'. Respondents were generally more comfortable with the term 'reputation', which they saw as more 'open', 'scholarly' and 'legitimate'. Branding on the other hand was perceived in some cases as 'manufactured' or a 'marketing ploy' and not directly relevant to their work as academics, as indicated in the following quote from a senior lecturer in School B.

\footnotetext{
I suppose I don't really engage with the branding side of it very closely... I suppose it's not aimed at me, and I think that the key message that I had from this [rebranding process] was that, you know, we're not rebranding it for you. We're rebranding it for other people outside the organisation.
}

In School A there was a general sense amongst academics that a 'soft' approach to branding was being used whereas in School B it was perceived as quite top-down. One academic in School A commented that a 'hard managerial' approach to branding elsewhere had 'not done them a great deal of good... they lost a lot of the good critical people.' In both institutions many academics were rather indifferent about the rebranding process. One respondent in School A echoed the earlier quote, stating that:

Branding is something that just floats above us... it is detached from what we do.

Others were more overtly opposed to branding and saw it as a waste of resource and a threat to academic integrity. Their response, however, was most likely through a lack of engagement with the brand rather than an outright challenge to those leading the rebranding efforts. Despite their ambivalence, however, a number did use the school PowerPoint and style templates, although rather selectively and generally in relation to teaching and promotion activities than research presentations, as illustrated below. 
I don't [use the template for research presentations]. It's a positive decision not to do that because I don't think its, you know I always say at the beginning of a presentation that I work at [School B] but I'm not owned by [the institution].

In School B faculty were invited to reflect on the manner in which personal profiles and photographs were used on the newly redesigned website. This exposed a tension between perceptions of themselves as individual academics and as members of an organisation. As the main producers of the scholarly work on which the school builds its reputation, a number of respondents expressed concern about how personal stories and images were appropriated for organisational purposes. A male professor referred to this as 'free aesthetic labour' for which he had no contract and went on to say:

[Whilst] I am generally happy to see myself represent the university in this way I do wish that more thought would go into how this works, and have some say in how my own image might be used - after all, it's my image.

In a related incident a female lecturer (on a probationary contract) who objected strongly to her image being used to represent the school reported being reduced to tears when, after being directed via personal email from the (male) dean that this was not optional, was requested by the male photographer to 'look sexy'. Subsequent investigation indicated that whilst she was not the only person to have objected to having her photo taken other, more senior academics, had been successful in resisting these demands.

These two contrasting examples illustrate the complex ways in which power and gender play out in the branding process and indicate the subjective emotional response to 'being branded' that usually remains hidden in accounts that represent branding as a professional activity. 
In both cases it would appear that those people most actively involved with the (re)branding process, apart from members of the senior management team, were in professional and support roles rather than academic faculty. A manager in School A, for example, remarked that branding and related activities were very important to administrators as it:

$\ldots$ gives them an identity [and] they know where they are ... how good we are ... and how important they are.

For managers and professional administrators, branding was seen as a professional activity. This was illustrated through the desire to use professional brand agencies to help develop and articulate the brand rather than relying on internal expertise (including that of academics in marketing specialisms). At the heart of these reforms was a desire to project a more consistent and 'business-like' image to potential students and partners, as indicated in the following quote from a member of professional services in School B:

I want to represent the school and show that we are professional... I'm giving out a message that I'm part of a business school which has a sort of corporate feel... I want them [a potential partner institution] to think that we come across as professional and equal to them.

In School B many of the people centrally involved in branding were relatively new to the institution and in a number of cases on short-term contracts. This is perhaps surprising and of concern as their actions were intended to fundamentally shift the school's presentation of itself both internally and externally, and may belie the fact that academics are the people most actively involved in delivering on the brand promise through their teaching and research.

The rebranding process, especially at School B, was regarded as an opportunity to (re)craft a compelling and distinctive narrative about the school, as indicated in the following quote from the marketing manager: 
I was picking out the best of each area really and just trying to make that more confident, more powerful, and slightly less apologetic.

A number of interviewees, however, expressed concern about the extent to which this narrative matched the reality of the school, as illustrated in the following comment:

I don't know what research has gone behind it. That's not been communicated, and why they've decided to do what they've done with it really.

In School A, while research excellence and rankings took centre-stage, there were less explicit attempts to construct a single narrative but key messages from managers and leaders included the positive culture, ethics and good citizenship and the relatively small size which was linked to a friendly and supportive environment. There was evidence in both schools of balancing multiple attributes as well as the tensions arising between 'academic' and 'business' values in the school.

\section{Student perspectives}

In this section we explore student perspectives on the branding process, focussing particularly on the views of undergraduates who have become key targets for university brand messages since the increase in student fees and for whom the brand is perhaps most significant for future career prospects.

In School B participants on a second year management degree attended a presentation by the dean on the school's new vision and strategy and were then asked to write a 500 word reflective assignment on (a) how well the vision reflected their own purpose and (b) to what extent it reflected the purposes of other stakeholders in the business school. Analysis of scripts revealed three main tensions in their reflections. 
Firstly a tension was noted between actual and aspirational identities. The presentation and assignment provided students the opportunity to reflect on their sense of association with the school. There were variations in how they responded, with some expressing a clear sense of connection others a sense of exclusion. Above all, however, students reported an aspiration for belonging rather than a strong sense of actual identification.

A second tension existed between perceptions of stability and change. Many students were ambivalent about the potential impact of changes to the school vision and mission on their current and future experience, as indicated below.

An increase in numbers may depersonalise the experience, hindering my purpose for personal growth.

For those students registered on programmes elsewhere in the university the business school vision and strategy was seen as potentially threatening or alienating:

I do not feel that I belong to the business school as a whole. I am not closely connected with their identity as I feel like a bit of an outsider.

A third tension was noted between current and future needs and aspirations. As indicated in the first point, students aspired towards a sense of 'belonging' during their studies yet several noted that the benefits of this membership are most important after graduation, as illustrated in the following quotes:

Lifting the profile of the school on a world stage [will make] it easier for myself and other subsequent leavers to attain employment even in current economic conditions

When I become alumni [sic] the enhanced image of [the school] will directly impact on the significance of my degree to potential employees. 
The student comments documented above highlight the fluid and ambiguous nature of brand association. They articulate a sense of connection with and against the image presented to them of the business school and recognition of the brand as an important source of identity both now and for the future. Their lack of influence over how this brand image is maintained and developed was a source of anxiety in several cases, and some voiced dismay at their lack of involvement in the review of strategy and brand.

\section{Discussion}

In Bourdieu's framework, actors, structures, resources in the form of capital, and cognitive predispositions in the form of habitus, all combine to lead our analysis away from unified field logics and homogenous sets of beliefs towards a more complex view that allows for contestation, heterogeneity and ambiguity. Branding in this sense can be seen as an important classificatory mechanism working through capital and strategic position-taking which diffuses as well as challenges norms and practices.

In both case studies branding was initiated by academic leaders (in particular deans) and implemented by professional administrators and consultants. Brand messages that were externally projected drew on the core internal attributes and scientific capital most highly valorised in the field to position research as the fulcrum around which other brand attributes clustered. Institutional rankings, while generated by external sources were also prominent as a device for leveraging organisational position in the hierarchy of business schools competing for reputational capital. Internal embedded cultural attributes such as good citizenship were also encompassed as part of the qualities, if not distinctiveness, of the brand. Managers were aware of the tensions between the academic components of the brand (such as scholarship) and the attributes linked to the corporate world (such as student services and accommodation) and endeavoured to juggle these in accordance with different constituencies and contexts. In 
Bourdieu's terms, branding as an externally generated mechanism was implemented by incorporating non-academic attributes while at the same time re-inscribing the dominant scientific capital in the field.

This approach is consonant with the boundary-spanning role of deans in the multilayer context of university leadership (Bolden, Petrov \& Gosling, 2008). In addition to representing the interests of the school horizontally, in relation to other faculties, and vertically in relation to the university hierarchy, the dean (together with senior colleagues) mediates relations with diverse external interest groups ranging from industrial research partners (actual and potential) to HE partners (which may be perceived as both collaborators and competitors). The brand does not define this context, it is rather part of the semantic material through which leadership is crafted, distributed and asserted, thus pointing to the importance of the 'collective' or 'social' nature of the text, or brand. It finds its identity, or distinctiveness, not only through difference, but also through similarity; 'it evolves out of the interaction between self and other' (Kornberger, 2010: 97).

As Forbes (2012: 359) has argued, since the 'true' meaning of the brand does not exist it 'cannot be created and controlled by the university's managers alone; rather, it must be continually co-created.' An appreciation of the negotiated, contingent and interest-laden nature of branding may go some way to explain why academic interactions and responses to branding was so ambiguous. As the findings from this study indicate, for some academics (particularly those with the highest forms of scientific capital) branding work was avoided whereas for others it was selectively appropriated in order to renegotiate their position in the field.

In School B, the manner in which academics were asked to engage in branding work through the use of their image and personal statements on the school website revealed tensions between the relative value attributed to different forms of capital. In this case 
academics were required to be photographed in posed settings that conveyed the required brand image of the organisation. This 'aesthetic labour' (Pettinger, 2004) drew attention away from the 'academic' capital typically associated with credibility and reputation as a scholar, and mobilised what might be referred to as 'sexual' or 'erotic' capital. Erotic capital (Hakim, $2010 \mathrm{a}, 2010 \mathrm{~b}$ ) refers to attributes of attractiveness and allure that lend advantages to an individual in social and economic life. Green $(2008,2013)$ points out that these are not simply individual traits, but that they are rendered 'capital' by being properties of a 'field' (Bourdieu, 1977) in which they are valued - a field that is intensely stratified by inequalities of power, specifically regarding images that carry meanings associated with gender and race (Michael, 2004). Hakim (2010a, 2010b) argues that individuals may deploy their erotic capital for their own benefit, and some academics may see institutional websites as an opportunity in this regard.

For academics who were also managers, branding attributes linked to external ranking and economic criteria were selectively deployed in their recruitment, teaching and engagement activities but often excluded in their capacity as researchers. Administrators and academics with less scientific capital on the other hand tended to engage enthusiastically with the rebranding process, seeing it an opportunity to demonstrate their professional expertise and as a means for (re)negotiating the relative status accorded to other forms of capital, thereby enhancing their position in the field. These insights suggest a more fluid engagement with the brand than might normally be assumed, and an explicit use of brand-related materials in 'identity work' (Sveningsson \& Alvesson, 2003) for academics, managers, administrators and students alike. The findings above point to the significance of habitus in orienting individuals to respond to branding as a locus of struggle with the potential to codify or legitimise the appropriate capital for membership and dominance in the field. 
It is suggested therefore, on the basis of this small study, that staff in various roles make use of brand and branding processes as resources to bolster their own interests. As we have seen, one effect of the significant concern about branding is to direct material resources towards branding processes and to other activities that are justified by reference to their contribution to 'the brand'. In so far as leadership is distributed in universities, it is distributed according to control of budgets, and especially to lines of expenditure that are open to interpretation and extension beyond the financial year-end (Gosling et al., 2009). Thus the 'fluid engagement with the brand' referred to above is an engagement that, for leaders, flows along a topography defined by budgets. This is just one of the ways in which brands are coproduced within the milieu of university life. While we have addressed some of the ways in which this is accomplished amongst staff, and student perceptions of the outcomes of this accomplishment, we have not explored ways in which students are involved in the coproduction of the brand or the links between institutional reputation and sub-brands. These are both important areas for further research.

\section{Conclusion}

By applying Bourdieu's framework to these case studies it is possible to see how the nature of the brand and responses to the brand are shaped by both individual agency and organisational structure. Access to different forms of capital contribute towards an individual's level of power and influence within a given field as well as directing likely action. For those people in research-active academic roles there may well be a tension between their engagement with the brand in relation to different parts of their role (as researcher, teacher, manager) and an interaction between their ownership of different types of capital (academic, scientific, erotic, etc.). 
In analysing the ways in which managerial practices such as branding operate within universities we may be able to shed light on the ways in which discourses and practices construct, frame and transform the context in which academic work and leadership occur (Fairhurst, 2009). Branding offers an important lens to analyse some of the effects of the restructuring of HE. In a post Keynesian era the idea that public universities ought to be organized and managed as business enterprises is gaining widespread influence amongst university managers. An analytical focus on the interaction of branding with the organizational processes, practices and leadership in HE has the potential to generate important insights about a sector caught between state control and market competition (Naidoo, 2008). Previous research has revealed that leadership and management processes will only succeed in engaging academics (and through them students and other stakeholders) in so far as they are perceived to enhance the quality and reputation of academic work (Bolden et al., 2012). This presents university leaders with a dilemma, arguably even more so in business schools. While accreditations, rankings and media recognition are derived from performance in defined ways, very few are explicitly related to the academic content of the work itself and rely, instead, on proxies such as journal publications, research income and student satisfaction scores. Leaders in pursuit of the 'brand' may well find themselves drawn to manage the performance and priorities of their colleagues in ways that are precisely contrary to what is required to engender increased commitment amongst key academic staff. Relatedly, it would be worth considering a question raised by several of our respondents of whether branding is focussed more on rhetoric than reality. We would argue, however, that even if the relationship between branding and actual practice is tenuous, branding activities nevertheless have material effects and consequences which merit further investigation. At the very least, institutions have a choice between investing resources in enhancing their brand image or on actual improvement of teaching and research. In all 
likelihood they will try to do both, however, as competition intensifies the temptation for selective representation and even falsification becomes stronger (Gioia \& Corley, 2002). Another crucial area for research, therefore, is the extent to which branding and associated activities imported from the business sector may ultimately undermine core values of HE and the potential of academics and universities to retain their capacity for objectivity and critique.

In conclusion we have argued that corporate branding may be used by university leaders to enhance the external profile of the institution and to drive internal culture change. By exploring the branding process within two English business schools from the perspectives of academics, management and professional staff, and students, we have highlighted some of the inherent tensions and complexities of such an approach for leadership. In particular, we have suggested that whilst the outcomes of branding are most significant for academics and students, and it is they who will ultimately deliver on (and reap the benefits of) the brand promise, they are frequently ambivalent or disengaged from the branding process. While branding is portrayed as a 'professional' activity - one based on objectivity and reason - the response to branding, and 'being branded', is frequently subjective, emotional and pervaded by power relations (Sullivan, Gosling \& Schroeder, 2013). By identifying (re)branding as a mechanism for culture change and the incorporation of an additional range of actors into university leadership and management this paper also contributes to an understanding of the ways in which leadership is 'distributed' within HE and the various forms in which agency can be asserted and power negotiated.

\section{References}

Bolden, R., Gosling, J., O’Brien, A., Peters, K., Ryan, M. \& Haslam, S.A. (2012). Academic Leadership: Changing conceptions, identities and experiences in UK higher education, London: Leadership Foundation for Higher Education. 
Bolden, R., Petrov, G. \& Gosling, J. (2008). Tensions in higher education leadership: towards a multi-level model of leadership practice, Higher Education Quarterly, 62(4), 358376.

Bourdieu, P. (1977). Outline of a Theory of Practice. Cambridge: Cambridge University Press.

Bourdieu, P. (1986). The forms of capital, in Richardson, G.R. (Ed.) Handbook of Theory and Research for the Sociology of Education. New York: Greenwood Press.

Bourdieu, P. (1988). Homo Academicus. Cambridge: Polity Press.

Bourdieu, P. (1996). The State Nobility. Cambridge: Polity Press.

Deem, R. and Brehony, K. J. (2005). Management as ideology: the case of 'new managerialism' in higher education, Oxford Review of Education, 31 (2), 217-235.

Fairhurst, G.T. (2009). Considering context in discursive leadership research, Human Relations, 62(11): 1607-1633.

Forbes, J. (2012). Structure and Agency in the Brand Box: a self-ethnography of university branding. Unpublished $\mathrm{PhD}$ thesis, University of Exeter.

Gioia, D.A. and Corley, K.G. (2002). Being good versus looking good: business school rankings and the Circean transformation from substance to image, Academy of Management Learning \& Education, 1, 107-120.

Gosling, J., Bolden, R. \& Petrov, G. (2009). Distributed leadership: what does it accomplish? Leadership, 5(3), 299-310.

Green, A. I. (2008). The social organization of desire: the sexual fields approach, Sociological Theory, 26: 25-50. 
Green, A. I. (2013). 'Erotic capital' and the power of desirability: why 'honey money' is a bad collective strategy for remedying gender inequality, Sexualities, 16(1-2), 137-158.

Hakim, C. (2010a). Erotic Capital, European Sociological Review, 26(5), 499-518.

Hakim, C. (2010b). Attractive forces at work, Times Higher Education, $3^{\text {rd }}$ June.

Hemsley-Brown, J. \& Goonawarddana, S. (2007). Brand harmonization in the international higher education market, Journal of Business Research, 60, 942-948.

Hemsley-Brown, J. \& Oplatka, I. (2006). Universities in a competitive global marketplace: a systematic review of the literature on higher education marketing, International Journal of Public Sector Management, 19(4), 316-338.

Jevons, C. (2006). Universities: a prime example of branding gone wrong, Journal of Product \& Brand Management, 15(7), 466-467.

Kornberger, M. (2010). Brand Society: How brands transform management and lifestyle. Cambridge: Cambridge University Press.

Lumby, J. (2012). What Do We Know About Leadership In Higher Education? The Leadership Foundation for Higher Education's research. London: Leadership Foundation for Higher Education.

Lumby, J. (2013). Distributed leadership: the uses and abuses of power, Educational Management Administration \& Leadership, 41, (5/6), in Press.

Michael, R. T. (2004). Sexual capital: an extension of Grossman's concept of health capital, Journal of Health Economics, 23(4), 643-652.

Morgen, J. (2011). Times Higher Education World Reputation Rankings, Times Higher Education, $10^{\text {th }}$ March. 
Naidoo R (2003). Repositioning higher education as a global commodity: opportunities and challenges for future sociology of education work, British Journal of Sociology of Education, 24(2), 249-259.

Naidoo, R. (2008). The competitive state and the mobilised market: higher education policy reform in the United Kingdom (1980-2007), Critique Internationale. Presses de Sciences Po., 47-65.

Naidoo, R., Shankar, A. \& Veer, E. (2011). The consumerist turn in higher education: policy aspirations and outcomes, Journal of Marketing Management, 27 (11-12), 1142-1162

Pettinger, L. (2004). Brand culture and branded workers: service work and aesthetic labour in fashion retail, Consumption, Markets and Culture, 7(2), 165-184.

Sullivan, K., Gosling, J. \& Schroeder, J. (2013). On being branded, Scandinavian Journal of Management, 29 (2), 121-122.

Sveningsson, S. \& Alvesson, M. (2003). Managing managerial identities: organizational fragmentation, discourse and identity struggle, Human Relations, 56(10), 1163-1193

Temple, P. (2006). Branding higher education: illusion or reality? Perspectives, 10(1), 15-19.

Waeraas, A., \& Solbakk, M. (2009). Defining the essence of a university: lessons from higher education branding, Higher Education, 57, 449-462. 